\title{
Direct incentive-compatible mechanism for innovator-investor bargain in an innovation investment system
}

\author{
Alim Gurtuev* \\ Institute of computer science and problems of regional management, KBSC RAS, 360004, Nalchik, \\ Russia.
}

\begin{abstract}
The functioning of the system of innovation investment, where an objective evaluation of an investment project containing new knowledge is impossible both for the investor and the innovator, currently is a matter of great interest. While for traditional industries, the use of statistical data is a satisfactory approach to the problem of uncertainty, for innovation projects this method isn't applicable due to the natural absence of a valid statistical base. The practice shows that the empirical mechanisms used for innovation projects are rarely used for investing in traditional industries and vice versa. In this connection, there arises the problem of development an effective mechanism for financing innovation projects. We developed such a mechanism for the innovator-investor system in the form of a Bayesian non-cooperative repeating game with recalculated payments. The equilibrium parameters for any period of the given game are obtained. It is shown that, depending on the a priori estimates of the type of project, four different equilibria are possible in any particular period of that game. Therefore, using the strategy of adjusting $a$ priori estimates of the investor and innovator on the basis of the Regret Matching rule, equilibrium for this finite Bayesian game is obtained.
\end{abstract}

\section{Introduction}

Financing of any commercial project assumes the uncertainty of the future. The emergence of new substitute products, actions of competitors, legislative innovations, environmental changes, and currency rate fluctuations - all these changes in the external environment should be taken into account when making an investment decision.

However, for established industries and markets, it is often implicitly assumed that volatility of the external environment will be insignificant, critical changes are considered "black swans" and generally omitted from the calculations [1-3]. To name a few examples - Russian companies did not take into account the possibility of conflict with Ukraine and its consequences (both legislative and monetary) when placing loans in foreign banks; Freon manufacturers did not take into account the possibility of a large-scale scandal with ozone holes; plans for Shtokman field didn't consider increased efficiency of shale gas production technologies; investors in subprime mortgages did not take into account the

\footnotetext{
*Corresponding author: alemao@mail.ru
} 
risks of the market collapse. The list can be continued, these situations are widely known, and a posteriori it often seems that in some cases there were mistakes in decision-making. But in the vast majority of cases, changes in the external environment are really insignificant. Although the market for subprime mortgages was similar to the bubble as early as 2003 [4], it continued to grow steadily for another 4 years [5]. The danger of a fullscale (and in the last couple of years - nuclear) war with North Korea was existed for several years, but investments in enterprises located on the territory of South Korea, however, do not decrease [6].

But for the innovation projects things are completely different. Decisions are based on evaluative and indefinite reasoning [7,8]. The investor should evaluate demand for the future, in most cases, not yet formed, market, as well as the likelihood of any technological changes that could critically affect this future market. Under these conditions, it is impossible to obtain a non-biased knowledge of the demand for a particular innovative product [9-11]. Moreover, because of the uncertainty of the existing knowledge at present, it is impossible to obtain objective evaluation of the technological solution on which the innovation project is based [12]. Thus, while for traditional industries, the use of statistical data on past similar projects is a satisfactory approach to the problem of uncertainty, for innovative investment this method isn't applicable due to the natural absence of a valid statistical base.

Indeed, the practice of the investment process in the OECD countries, Russia, India and China, shows that the empirical mechanisms used in innovative investment (multi-stage investment, investor pools, diversified ownership packages, mentors) are rarely used for investing in traditional industries and vice versa [13]. In this connection, there arises the problem of development an effective mechanism for financing innovation projects.

\section{A general economic mechanism}

In economics, a mechanism is a set of formal rules describing the functional dependence of decisions made by economic agents on information known to these agents [14]. In this sense, any economic institution can be formally described as a certain mechanism, which makes the theory of mechanisms a suitable basis for both a comparative analysis of various mechanisms and for determining the optimal mechanism for innovation investment, since information constraints of economic actors are considered in conjunction with resource constraints.

It is proved in literature that for every Bayes-Nash equilibrium in given economic mechanism there is an equivalent, incentive-compatible direct-revelation mechanism [15]. Such a mechanism is a system of agents with independent utility functions and a mediator that can communicate with each of the agents confidentially and independently, and it is not profitable for each agent to report false information about itself or to deviate from the mediator's recommended action.

Such a mechanism $\boldsymbol{\mu}: \boldsymbol{T}_{1} \times \ldots \times \boldsymbol{T}_{\boldsymbol{n}} \rightarrow \boldsymbol{C}$ for the innovator-investor system can be described as follows:

1) The set of possible strategies $\boldsymbol{S}_{\boldsymbol{i}}$ for the agent (innovator or investor) $\boldsymbol{i}$ match with the set of its possible types $\boldsymbol{T}_{\boldsymbol{i}}$

2) For each agent $\boldsymbol{i}$ and each pair of types $\boldsymbol{t}_{\boldsymbol{i}}$ and $\boldsymbol{r}_{\boldsymbol{i}}$ of $\boldsymbol{T}_{\boldsymbol{i}}$, the information incentive constraint (adverse selection constraint) is satisfied:

$$
\sum_{t_{-i} \in T_{-i}} p_{i}\left(t_{-i} \mid t_{i}\right) u_{i}(\mu(t), t) \geq \sum_{t_{-i} \in T_{-i}} p_{i}\left(t_{-i} \mid t_{i}\right) u_{i}\left(\mu\left(t_{-i}, r_{i}\right), t\right)
$$


3) For the mediator $\boldsymbol{m}$ and any function $\boldsymbol{\delta}: \boldsymbol{C} \rightarrow \boldsymbol{C}$ (the function of the choice from possible combinations of agents' actions), a strategic restriction on incentives (moral hazard constraint) is performed:

$$
\sum_{t \in T} p_{m}(t) u_{m}(\mu(t), t) \geq \sum_{t \in T} p_{m}(t) u_{m}(\delta(\mu(t)), t)
$$

\section{The model}

One of the very important problems in financing innovative projects is the problem of cutting off so-called "fake projects", projects that are deliberately fraudulent and impracticable [16]. These are projects on the basis of knowingly unrealizable concepts, which are aimed only at obtaining financing, and then in a few years, either report on the impossibility of completing the project for the reasons beyond the "inventor" capabilities or to issue a product that does not have any real innovation in it (the infamous Petrik filter, for example, is a product of the latter type).

On this basis, let's define the fake project as a project aimed only at obtaining irrevocable financing, which, according to its creators' private knowledge, does not have commercial prospects.

Let's consider a mechanism for investment in innovative projects when projects pool consisted on two projects types - good projects and fake projects, and these types are indistinguishable for investor. Such a situation can be modeled by a game with incomplete information, or Bayesian game. The hidden information here determines the type of player $[17,18]$.

Let $\boldsymbol{N}$ be the set of players. Each player $\boldsymbol{i}$ of $\boldsymbol{N}$ has a number of possible actions (strategies) $\boldsymbol{S}_{\boldsymbol{i}}$. The hidden information that a player have from the very beginning can be represented as a set of $\boldsymbol{T}_{\boldsymbol{i}}$ for each player $\boldsymbol{i}$ of $\boldsymbol{N}$. Thus, the Cartesian product $\boldsymbol{S} \times \boldsymbol{T}$ defines all possible player profiles.

Next, let's introduce the probability function $\boldsymbol{p}_{\boldsymbol{i}}$, and call it the belief which is the mapping of $\boldsymbol{T}$ into $\Delta\left(\boldsymbol{T}_{-i}\right)$, where $\boldsymbol{\Delta}\left(\boldsymbol{T}_{-i}\right)$ is the probability distribution over all combinations of possible types different from $\boldsymbol{i}$. This function formally describes the nature of the hidden information in this game. If player $\boldsymbol{i}$ is of type $\boldsymbol{t}_{\boldsymbol{i}}, \boldsymbol{p}_{\boldsymbol{i}}$ is the conditional probability that the rest of the players have types that are components of the vector $\boldsymbol{t}_{-i}$. For example, $\boldsymbol{p}\left(\boldsymbol{t}_{-i} \mid \boldsymbol{t}_{\boldsymbol{i}}\right)$ is the conditional probability that the real type distribution will be $\boldsymbol{t}_{-i}$ if player $\boldsymbol{i}$ is of type $\boldsymbol{t}_{\boldsymbol{i}}$.

The preferences of each player $\boldsymbol{i}$ of $\boldsymbol{N}$ are usually modeled by some utility function which is a mapping of $\boldsymbol{S} \times \boldsymbol{T}$ to the set of real numbers $\mathbf{R}$. Denoting this function as $\boldsymbol{u}_{i}(\boldsymbol{s}, \boldsymbol{t})$, we can interpret its value as the payoff for the player $\boldsymbol{i}$ at possible actions $\boldsymbol{s}$ and the players profile $t$.

All of the above fully defines the Bayesian game with consistent preferences, which can be written in the following form:

$$
G^{h}=\left\langle N,\left(S_{i}\right)_{i \in N},\left(T_{i}\right)_{i \in N},\left(p_{i}\right)_{i \in N},\left(u_{i}\right)_{i \in N}\right\rangle
$$

where $N$ - the set of players (investor and innovator in our case); $\left(\boldsymbol{S}_{i}\right)_{i \epsilon N}-$ the set of possible strategies (for the innovator, there are two strategies - participation or non-participation, and for the investor - a set of strategies that differ in the size and structure of investment, from non-participation, to full upfront financing); $\left(\boldsymbol{T}_{\boldsymbol{i}}\right)_{i \epsilon N}-$ the set of possible player types (in our case for the investor this is only one type, for the innovator there are two types, $\boldsymbol{H}$ (high) and $\boldsymbol{L}$ (low), determined depending on the future success of the project; $\left(\boldsymbol{p}_{\boldsymbol{i}}\right)_{i \in N}$ - players' beliefs about the types of other players. All players have the same evaluation of the distribution of player types. This assumption reflects the fact that all players have access to the same information about the world as a whole (technology, economy, and science) and about other players, and proceed from the premise of the 
rationality of other players; $\left(\boldsymbol{u}_{i}\right)_{i \epsilon N}$ - players' utility functions. Note that in the case if the type of innovator is $L$, the payoff for investor is negative; As $N, S_{i}, T_{i}$ are finite, the game is finite.

Consider such a game when innovators of $\boldsymbol{L}$ type are fake projects providers. Both types of innovators make decisions about following:

- The requested amount of funding (estimation of the minimal cost of implementing $\boldsymbol{C}_{\min }$ and the request for premium $\boldsymbol{C}_{\text {extra }}$. Let's assume that the innovators remuneration and other direct benefits received by the innovator during the project implementation are included in $\boldsymbol{C}_{\text {extra }}$;

- Participation in project expenses $\boldsymbol{C}_{\boldsymbol{e}}$;

- The share $\boldsymbol{S}$ offered to investors;

- A priori estimation of project implementation probability $\boldsymbol{q}$;

- Estimation $\boldsymbol{v}_{\boldsymbol{e}}$ of the project NPV in the case of successful implementation;

- Estimation $\boldsymbol{\sigma} \boldsymbol{v}_{\boldsymbol{e}}$ of the average deviation from project NPV;

- Estimation $\boldsymbol{t}_{\boldsymbol{e}}$ of the number of time periods until the successful project implementation.

Let's set following conditions for innovators of type $\boldsymbol{H}$ :

- $\mathrm{C}_{\text {min }}>0, \mathrm{C}_{\text {extra }}>0,0<\mathrm{C}_{\text {extra }}<\mathrm{C}_{\text {min }}, \mathrm{C}_{\mathrm{e}}<<\mathrm{C}_{\text {min }}$

- $0<\mathrm{q}<1, \mathrm{v}_{\mathrm{e}}>>\left(\mathrm{C}_{\mathrm{extra}}+\mathrm{C}_{\min }\right), \sigma \mathrm{v}_{\min }<\sigma \mathrm{v}_{\mathrm{e}}<\mathrm{v}_{\mathrm{e}}, \sigma \mathrm{v}_{\min }<\left(\mathrm{C}_{\mathrm{extra}}+\mathrm{C}_{\min }\right), \mathrm{t}_{\mathrm{e}}>0$

And let's set following conditions for innovators of type $\boldsymbol{L}$ :

- $\mathrm{C}_{\text {min }}=0, \mathrm{C}_{\text {extra }}>0, \mathrm{C}_{\mathrm{e}}<<\mathrm{C}_{\text {extra }}$

- $\mathrm{q}=0, \mathrm{v}_{\mathrm{e}}=0, \sigma \mathrm{v}_{\mathrm{e}}=0, \mathrm{t}_{\mathrm{e}}>0$

Let there be one type of investors making decisions of:

- Project financing (full financing, partial financing with a share of $\boldsymbol{s}_{i}$, restrain from the project);

- Bargaining with the innovator or not;

- A priori estimation of project implementation probability $\boldsymbol{p}$;

- Estimation $v_{i}$ of the project NPV in the case of successful implementation;

- Estimation $\sigma v_{i}$ of the average deviation from project NPV;

- Estimation $\boldsymbol{t}_{i}$ of the number of time periods until the successful project implementation.

- Discount parameter for uncertainty over time

Let's assume for the simplicity that $\boldsymbol{v}$ and $\boldsymbol{\sigma} \boldsymbol{v}$ values are similar for investor and $\boldsymbol{H}$-type innovator.

Since different players have different knowledge about the payoffs (the investor believes that the project is implemented with probability $\boldsymbol{p}$, and the innovator - with probability $q$ ), then for the investor and the innovator, the expected payoff will be different. Thus a posteriori equilibrium will differ from the ex interim equilibrium. It is assumed that the players know this (similarly to the Milgrom game with the sophisticated novice [19]).

In the normal form, one period of the game is shown in Table 1. There $s_{i}$ is the share of the project for investor $\boldsymbol{i} ; \boldsymbol{P}^{\boldsymbol{b}}$ - estimation that the bargain will be successful; $\boldsymbol{s}_{\boldsymbol{i}} \boldsymbol{i}$ - extra share given to the investor $\boldsymbol{i}$ after the bargain.

Assume that the share of fake projects in the overall flow of projects is $\boldsymbol{p}^{f}$. The probability of detecting a fake project at the project evaluation stage is $\boldsymbol{r}_{\boldsymbol{f}}$ (assume that there is no false positive), with costs $\boldsymbol{c}^{f}$. Let $\boldsymbol{C}$ be the total costs of the project, declared by the innovator. Then, for the investor, the game looks following:

With probability $\boldsymbol{g}=\left(1-\boldsymbol{p}^{f}\right) /\left(1-\boldsymbol{r}^{f} \boldsymbol{p}^{f}\right)$ he is playing with $\boldsymbol{H}$-type innovator and, as $\frac{\left(\mathbf{1}-\boldsymbol{P}^{b}\right) \boldsymbol{C}_{e}}{\boldsymbol{B}_{e}}>0$, and players are rational and sophisticated, will seek cost-participation strategy from innovator under conditions, that we describe later in the paper. 
With probability $\mathbf{1 - g}=\left[(1-\boldsymbol{r}) \boldsymbol{p}^{f}\right] /\left(1-\boldsymbol{r} \boldsymbol{p}^{f}\right)$ he is playing with fake project provider, and have dominant strategy to not participate.

Table 1. One period of Bayesian game between investor and innovator

\begin{tabular}{|c|c|c|c|}
\hline & Support (partial or full, $\boldsymbol{S}=\Sigma \boldsymbol{s}_{\boldsymbol{i}}<1$ ) & Decline & Bargain $\left(\boldsymbol{P}^{\boldsymbol{b}}<1,0<\boldsymbol{s}^{\boldsymbol{b}}<1, \boldsymbol{S}=\sum \boldsymbol{s}_{i}+\boldsymbol{s}_{\boldsymbol{i}}^{\boldsymbol{b}_{i}<1}\right.$ \\
\hline $\begin{array}{l}\mathrm{H}-\text { Cost } \\
\text { participation } \\
\left(\boldsymbol{C}_{\boldsymbol{e}}\right)\end{array}$ & $\begin{array}{c}p^{*} S_{i}^{*} v_{i}-S_{i} *\left(C_{\min }+C_{e x t r a}-C_{e}\right) \\
q^{*}(1-S)^{*} v_{e}-C_{e}+C_{e x t r a}\end{array}$ & 0 & 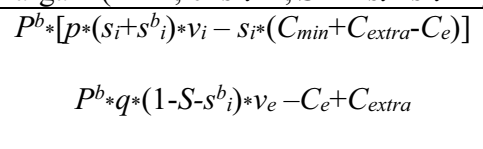 \\
\hline $\begin{array}{l}\mathrm{H}-\text { Costs } \\
\text { already incurred } \\
\qquad\left(\boldsymbol{C}_{\boldsymbol{e}}\right)\end{array}$ & $\begin{array}{c}p^{*} S_{i} * v_{i}-S_{i} *\left(C_{\min }+C_{\text {extra }}-C_{e}\right) \\
q *(1-S) * v_{e}-C_{e}+C_{\text {extra }}\end{array}$ & $-C_{e}$ & $\begin{array}{c}P^{b_{*}}\left[p *\left(s_{i}+s^{b}{ }_{i}\right) * v_{i}-S_{i} *\left(C_{\min }+C_{e x t r a}-C_{e}\right)\right] \\
P^{b_{*}} q^{*}\left(1-S-s^{b_{i}}\right) * v_{e}-C_{e}+C_{\text {extra }}\end{array}$ \\
\hline $\begin{array}{l}\mathrm{H}-\mathrm{No} \text { cost } \\
\text { participation }\end{array}$ & $\begin{array}{c}p^{*} S_{i} * v_{i}-S_{i} *\left(C_{\min }+C_{\text {extra }}\right) \\
q^{*}(1-S) * v_{e}+C_{\text {extra }}\end{array}$ & 0 & $\begin{array}{c}P^{b_{*}}\left[p *\left(s_{i}+s^{b}{ }_{i}\right) * v_{i}-s_{i} *\left(C_{\min }+C_{\text {extra }}\right)\right] \\
P^{b_{*}} q *\left(1-S-s^{b}{ }_{i}\right) * v_{e}+C_{\text {extra }}\end{array}$ \\
\hline $\begin{array}{c}\mathrm{L}-\text { Cost } \\
\text { participation }\end{array}$ & $p^{*} S_{i^{*}}^{*} v_{i}-S_{i^{*}}\left(C_{\min }+C_{\text {extra }}-C_{e}\right)$ & 0 & $\begin{array}{c}P^{b_{*}}\left[p *\left(s_{i}+s^{b}{ }_{i}\right) * v_{i}-s_{i} *\left(C_{\min }+C_{e x t r a}-C_{e}\right)\right] \\
-C_{e}+C_{\text {extra }}\end{array}$ \\
\hline $\begin{array}{c}\mathrm{L}-\text { Costs } \\
\text { already incurred }\end{array}$ & $\begin{array}{c}p^{*} S_{i *}^{*} v_{i}-S_{i^{*}}\left(C_{\min }+C_{\text {extra }}-C_{e}\right) \\
-C_{e}+C_{\text {extra }} \\
\end{array}$ & $-C_{e}$ & $\begin{array}{c}P^{b_{*}}\left[p *\left(s_{i}+s^{b}{ }_{i}\right) * v_{i}-S_{i} *\left(C_{\min }+C_{e x t r a}-C_{e}\right)\right] \\
-C_{e}+C_{\text {extra }}\end{array}$ \\
\hline $\begin{array}{l}\mathrm{L}-\text { No cost } \\
\text { participation }\end{array}$ & $p^{*} S_{i}^{*} v_{i}-S_{i}^{*}\left(C_{\min }+C_{\text {extra }}\right)$ & 0 & $\begin{array}{c}P^{b *}\left[p *\left(s_{i}+s^{b}{ }_{i}\right) * v_{i}-s_{i} *\left(C_{\min }+C_{e x t r a}\right)\right] \\
C_{\text {extra }}\end{array}$ \\
\hline
\end{tabular}

\section{Conclusion}

Thus, the game has four possible equilibria in any particular period:

With probability $g$ :

"Cost participation" - "Support" if:

$$
P^{b} \leq \frac{s_{i}\left(C_{i}-B_{i}\right)}{s_{i}\left(C_{i}-B_{i}\right)-s_{i}^{b} B_{i}} A N D \frac{S}{1-S-S^{b}} \leq P^{b} \leq \frac{S\left(B_{e}+C_{e}\right)}{B_{e}\left(1-S-S^{b}\right)+C_{e} S}
$$

"Cost participation" - "Bargain" if:

$$
P^{b} \geq \frac{s_{i}\left(C_{i}-B_{i}\right)}{s_{i}\left(C_{i}-B_{i}\right)-s_{i}^{b} B_{i}} A N D P^{b} \geq \frac{S\left(B_{e}+C_{e}\right)}{B_{e}\left(1-S-S^{b}\right)+C_{e} S}
$$

"Costs incurred" - "Support" if:

$$
P^{b} \leq \frac{s_{i}\left(C_{i}-B_{i}\right)}{s_{i}\left(C_{i}-B_{i}\right)-s_{i}^{b} B_{i}} A N D P^{b} \leq \frac{S}{1-S-S^{b}}
$$

"Costs incurred" - "Bargain" if:

$$
P^{b} \geq \frac{s_{i}\left(C_{i}-B_{i}\right)}{s_{i}\left(C_{i}-B_{i}\right)-s_{i}^{b} B_{i}} \text { OR } P^{b} \geq \frac{S}{1-S-S^{b}}
$$

With probability $\mathbf{1 - g}$ - investor restrains from the project.

So, we developed a mechanism for the innovator-investor system in the form of a Bayesian non-cooperative repeating game with recalculated payments and four ex interim 
equilibria in any particular game period, depending of player's estimations. Therefore, using the strategy of adjusting a priori estimates of the investor and innovator on the basis of the Regret Matching rule [20], equilibrium for this finite Bayesian game is obtained.

\section{References}

1. K. Arrow. Economic Inquiry, 20, 1, 1 (1982)

2. B. Greenwald, J. Stiglitz, A. Weiss. AER, 74, 2, 194 (1984)

3. J. M. Blatt. Financial Management, 8, 2, 66 (1979)

4. M. Comiskey, P. Madhogarhia. PS: Political Science and Politics, 42, 2, 271 (2009)

5. Y. Demyanyk, O. Van Hemert. The Review of Financial Studies, 24, 6, 1848 (2011)

6. D. Park, I. Kang. Asian Affairs, 27, 1, 3 (2000)

7. O. D. Hart, J. Moore. Econometrica, 56, 4, 755 (1988)

8. M. Seitz, M. Watzinger. Research Policy, 46, 1, 182 (2017)

9. N. Nunn. QJE, 122, 2, 569 (2007)

10. R. Gibbons, D.J. Roberts, ed. Handbook of Organizational Economics (Princeton University Press., Princeton, 2012)

11. E. Glaeser, S. Johnson, A. Shleifer. QJE, 116, 3, 853 (2001)

12. V. V. Acharya, K. Subramanian. The Review of Financial Studies, 22, 12, 4949 (2009)

13. L. Guiso, G. Parigi. QJE, 114, 1, 185 (1999)

14. R. Myerson. AER, 98, 3, 586 (2008)

15. T. Groves, et al. eds. Information, Incentives, and Economics Mechanisms: Essays in Honor of Leonid Hurwicz (University of Minnesota Press., Minneapolis, 1987)

16. A. O. Gurtuev, Z. Z. Ivanov, E. G. Derkach. Izvestiya KBNC RAN, 6, 45 (2017) (in Russian)

17. J. Harsanyi. Management Science, 13, 3, 159 (1967)

18. J. Harsanyi. Management Science, 14, 5, 320 (1968)

19. P. Milgrom. JEP, 22, 2, 115 (2008)

20. R. Porter, E. Nudelman, Y. Shoham. Games and Economic Behavior, 63, 2, 642 (2008) 